CZASOPISMO INŻYNIERII LA¿OWEJ, ŚRODOWISKA I ARCHITEKTURY JOURNAL OF CIVIL ENGINEERING, ENVIRONMENT AND ARCHITECTURE

JCEEA, t. XXXIII, z. 63 (1/I/16), styczeń-marzec 2016, s. 87-96

\author{
Agnieszka BURAKOWSKA ${ }^{1}$ \\ Maciej MACIAK ${ }^{2}$ \\ Lukasz MURAWSKI ${ }^{3}$ \\ Szymon DOMAŃSKI ${ }^{4}$ \\ Michał A. GRYZIŃSKI ${ }^{5}$
}

\title{
BADANIE OSŁONNOŚCI RADIACYJNEJ BETONÓW SPECJALNYCH
}

\begin{abstract}
W artykule przedstawiono wyniki badań właściwości osłonnych betonów eksperymentalnych przed promieniowaniem gamma, z wykorzystaniem zamkniętego źródła promieniotwórczego ${ }^{137} \mathrm{Cs}$. Do analiz sporządzono i opisano specjalne stanowisko badawcze o określonej geometrii. Do badań wykorzystano odpowiednio przygotowane próbki betonów ciężkich o zróżnicowanym składzie. W ramach prac przebadano piętnaście rodzajów betonów różniących się przede wszystkim zawartością kruszyw oraz gęstością objętościową. Na podstawie uzyskanych danych pomiarowych, dla poszczególnych prób betonów, otrzymano wartości grubości kolejnych warstw połówkowych (HVL) i dziesięciochłonnych (TVL). Z przeprowadzonych analiz wynika, iż najlepsze parametry osłonne w polu promieniowania gamma dla izotopu ${ }^{137} \mathrm{Cs}$ mają betony, z których kruszywem magnetytowym oraz barytowym. Betony te miały bardzo wysoką gęstość - powyżej $3300 \mathrm{~kg} / \mathrm{m}^{3}$. Gorszymi parametrami charakteryzowały się natomiast mieszanki zawierające w składzie tylko kruszywa zwykłe (serpentynit lub amfibolit), a ich gęstość nie przekraczała $2450 \mathrm{~kg} / \mathrm{m}^{3}$. Otrzymane wyniki badań, zgodnie z wcześniejszymi założeniami, wskazują, że wraz ze wzrostem gęstości materiału osłonowego warstwa HVL (odpowiednio TVL) zmniejsza się, co oznacza, że właściwości osłonowe materiału przed promieniowaniem gamma ulegają poprawie.
\end{abstract}

Słowa kluczowe: beton, osłony, promieniowanie gamma, pomiary eksperymentalne

\footnotetext{
${ }^{1}$ Autor do korespondencji/corresponding author: Agnieszka Burakowska, Narodowe Centrum Badań Jądrowych, ul. Andrzeja Sołtana 7, 05-400 Otwock, tel. 22 2731057, e-mail: agnieszka.burakowska@ncbj.gov.pl

${ }^{2}$ Maciej Maciak, Narodowe Centrum Badań Jądrowych

${ }^{3}$ Łukasz Murawski, Narodowe Centrum Badań Jądrowych

${ }^{4}$ Szymon Domański, Narodowe Centrum Badań Jądrowych

${ }^{5}$ Michał A. Gryziński, Narodowe Centrum Badań Jądrowych
} 


\section{Wprowadzenie}

Materiałami najpowszechniej stosowanymi w konstrukcjach budowlanych są beton i stal. Nie inaczej jest w przypadku projektowania i budowy osłon w obiektach jądrowych oraz w innych przypadkach, gdzie mamy do czynienia $\mathrm{z}$ wykorzystaniem promieniowania jonizującego (badania materiałowe, medycyna), a także przetwarzaniem i gromadzeniem odpadów promieniotwórczych na składowiskach. Ze względu na stosunkowo niski koszt produkcji i swój uniwersalizm, beton jest głównym materiałem stosowanym do budowy osłon przed promieniowaniem. Stosuje się go wszędzie tam, gdzie warunki eksploatacyjne i techniczne pozwalają na większe grubości osłon. W porównaniu z innymi materiałami odznacza się jednocześnie wysoką wytrzymałością, dobrymi właściwościami izolacyjnymi jak również możliwością nadania mu dowolnej formy. Betonowe elementy osłonowe muszą spełniać różnorodne wymagania dotyczące m. in. właściwości mechanicznych, szczelności, trwałości czy odporności w sytuacjach awaryjnych, odpowiadające przewidzianym okresom eksploatacji obiektu. W związku z tym, w przeciwieństwie do typowych konstrukcji budowlanych, betony osłonowe charakteryzują się specjalną kompozycją, gdzie obok cementu, piasku, wody i kruszywa, stosowane są specjalne wypełniacze (np. włókna i elementy stalowe, żużle, odpady hutnicze). Istotnym czynnikiem w przypadku betonów osłonowych jest przede wszystkim dobranie odpowiednich kruszyw. Mimo tego, że prace badawcze nad zastosowaniem betonu w budownictwie związanym z wytwarzaniem energii jądrowej rozpoczęły się w Polsce przed 1970 rokiem, w obliczu współczesnego poziomu wiedzy na świecie, cały czas istnieje zapotrzebowanie na krajowe badania w tej dziedzinie [1].

\section{Właściwości betonów ciężkich w konstrukcjach osłonowych}

Właściwości osłonowe betonów zmieniają się przede wszystkim w zależności od rodzaju zastosowanego kruszywa. $Z$ reguły są to ciężkie kruszywa naturalne zawierające minerały takie jak: baryt $\left(\mathrm{BaSO}_{4}\right)$ bądź rudy żelaza - magnetyt $\left(\mathrm{Fe}_{3}\left(\mathrm{Fe}^{2+} \mathrm{Fe}^{3+}\right) \mathrm{O}_{4}\right)$, hematyt $\left(\mathrm{Fe}_{2} \mathrm{O}_{3}\right)$, getyt $(\mathrm{FeOOH})$ i ilmenit $\left(\mathrm{FeTiO}_{3}\right)$, które charakteryzują się zwiększoną zdolnością zatrzymywania różnego rodzaju promieniowania. W Tabeli 1 przedstawiono różne rodzaje kruszyw zastosowanych do produkcji prób betonów eksperymentalnych. Do przygotowania mieszanek betonowych kruszywo było dodawane w różnych proporcjach i o zróżnicowanej frakcji, po czym zbadano właściwości osłonowe poszczególnych betonów.

Ze względu na dużą przenikliwość promieniowania gamma oraz neutronowego, a co za tym idzie, konieczność stosowania grubych i ciężkich osłon, istotnym staje się dobór najbardziej efektywnych materiałów osłonnych, spełniających jednocześnie wymagania eksploatacyjne. Poza tym, że betony osłonowe powinny stanowić skuteczną ochronę przed promieniowaniem jonizującym, muszą odznaczać się odpowiednią wytrzymałością i trwałością w warunkach oddzia- 
Tabela 1. Przykładowe rodzaje kruszyw zastosowanych w eksperymentalnych mieszankach betonowych Table 1. Examples of the types of aggregates used in experimental concrete mixture

\begin{tabular}{|l|l|l|}
\hline \multicolumn{1}{|c|}{ Rodzaj kruszywa } & \multicolumn{1}{|c|}{ Frakcja [mm] } & \multicolumn{1}{c|}{ Skład chemiczny } \\
\hline piasek kwarcowy & $0-2$ & $\mathrm{SiO}_{2}$ \\
\hline kruszywo amfibolitowe & $2-8 ; 8-16$ & $\mathrm{NaCa}_{2}(\mathrm{Mg}, \mathrm{Fe}, \mathrm{AL})_{3}(\mathrm{SiAl})_{8} \mathrm{O}_{22}(\mathrm{OH})_{2}$ \\
\hline kruszywo magnetytowe & $0-5 ; 5-16$ & $\left(\mathrm{Fe}_{3}\left(\mathrm{Fe}^{2+} \mathrm{Fe}^{3+}\right) \mathrm{O}_{4}\right)$ \\
\hline kruszywo barytowe & $0-16$ & $\mathrm{BaSO}_{4}$ \\
\hline kruszywo serpentynitowe & $0-2 ; 2-8 ; 8-16$ & $\begin{array}{l}\left(\mathrm{Mg}_{6}\left[(\mathrm{OH})_{8} / \mathrm{Si}_{4} \mathrm{O}_{10}\right]\right) \\
(\mathrm{Mg}, \mathrm{Fe})_{3} \mathrm{Si}_{2} \mathrm{O}_{5}(\mathrm{OH})_{4} \\
\left.\mathrm{Mg}_{6}\left[(\mathrm{OH})_{8} \mathrm{Si}_{4} \mathrm{O}_{10}\right]\right)\end{array}$ \\
\hline
\end{tabular}

ływania pozostałych czynników zewnętrznych. W związku z tym, że wieloletnie wystawienie na działanie promieniowania jonizującego wpływa na składniki i strukturę betonu, ma to tym bardziej istotne znaczenie. Składniki zastosowane do produkcji betonów osłonowych muszą zatem charakteryzować się odpowiednią jakością i przemyślanym doborem. Wiele podstawowych właściwości betonu jest zależnych nie tylko od rodzaju zaczynu cementowego, ale także od jakości i wielkości zastosowanego kruszywa [4]. Kruszywo powinno charakteryzować się odpowiednią czystością składu chemicznego. Wszelkie dodatki mineralne (np. domieszki minerałów ilastych czy węglanowych) mogą mieć znaczny wpływ na trwałość betonu w trakcie jego eksploatacji, powodując przemiany wtórne zarówno w cemencie jak i kruszywie, co może prowadzić do korozji stwardniałego betonu. Kruszywo nie może być także zanieczyszczone organicznie [4].

\section{Badanie osłonności przed promieniowaniem jonizującym}

Promieniowanie jonizujące definiuje się jako promieniowanie powodujące jonizację ośrodka materialnego, czyli powstanie jonu dodatniego lub ujemnego wskutek oderwania od lub dołączenia do obojętnego atomu co najmniej jednego elektronu. Przy czym należy zauważyć, że proces jonizacji może odbywać się bezpośrednio, jak w przypadku promieniowania cząstek obdarzonych ładunkiem elektrycznym (np. alfa, beta, ciężkie jony), ale również w sposób pośredni jak to ma miejsce $\mathrm{w}$ przypadku fotonów promieniowania elektromagnetycznego (X oraz gamma) czy promieniowania neutronowego. W przypadku promieniowania jonizującego pośrednio cząstki pierwotne oddziałują $\mathrm{z}$ ośrodkiem, wskutek czego wybijane są cząstki wtórne, które to już w procesie jonizacji bezpośredniej oddziałują z ośrodkiem.

W zależności od rodzaju promieniowania jak również jego energii sposób oddziaływania z ośrodkiem materialnym zmienia się w sposób znaczny. Ma to bezpośrednie przeniesienie na dobór materiałów osłonowych stosowanych w budownictwie specjalnym, takim jak w przypadku ośrodków jądrowych, 
w ośrodkach badań radiacyjnych czy obiektach medycznych wykorzystujących źródła promieniowania jonizującego.

\subsection{Odziaływanie promieniowania gamma $\mathrm{z}$ ośrodkiem materialnym}

Za pochłanianie promieniowania fotonowego $\mathrm{X}$ i gamma przez materię odpowiadają następujące zjawiska: efekt fotoelektryczny, efekt Comptona lub zjawisko tworzenia/anihilacji par elektron-pozyton. Wymienione wyżej oddziaływania wymagają interakcji z elektronami $\mathrm{z}$ odpowiednich powłok atomowych bądź przynajmniej obecności jądra atomowego. W związku z tym dla zwiększenia efektywności pochłaniania wymagana jest wysoka gęstość elektronowa osłony. Ciężkie pierwiastki takie jak ołów czy wolfram stanowią idealny materiał osłonowy przed promieniowaniem gamma, lecz ze względu na wysoki koszt i znaczny ciężar ich wykorzystanie w konstrukcjach budowlanych jest znacznie ograniczone. Warunek ten spełniają także inne materiały które w swoim składzie zawierają pierwiastki o dużej liczbie atomowej. W przypadku betonu są to bar $(\mathrm{Z}=56)$ i żelazo $(\mathrm{Z}=26)$, które stanowią podstawowe składniki kruszyw ciężkich. Zawartość odpowiednich pierwiastków w kruszywie pozwala na zmniejszanie grubości warstw betonu, zachowując jego właściwości mechaniczne.

\subsection{Badanie osłonności przed promieniowaniem gamma}

Podstawowymi parametrami określającymi właściwości osłonowe promieniowania jonizującego są HVL oraz TVL [5]. HVL (Half Value Layer) definiowany jest jako grubość materiału osłonowego wyrażona $\mathrm{w} \mathrm{cm}$, która powoduje osłabienie promieniowania o 50\%, odpowiednio TVL (Tenth Value Layer) definiowany jest jako grubość materiału osłonowego wyrażona $\mathrm{w} \mathrm{cm}$, która powoduje osłabienie promieniowania o 90\%. Parametry definiowane są w ten sposób dla promieniowania $\mathrm{X}$ oraz gamma.

\section{Metodyka badań}

Badania osłonności próbek betonowych wykonane zostały w Hali Kalibracyjnej Narodowego Centrum Badań Jądrowych zgodnie z metodologią opracowaną na potrzeby badania osłonności różnego rodzaju materiałów osłonowych [2]. Jest to pomieszczenie badawczo-wzorcujące wyposażone m.in. w ławę kalibracyjną, irradiator oraz izotopowe źródła promieniotwórcze. W przypadku badania osłonności przed promieniowaniem gamma wykorzystano wspomniany irradiator oraz źródło promieniowania gamma ${ }^{137} \mathrm{Cs}$. Źródło to emituje promieniowanie gamma o energii $661,7 \mathrm{keV}$. Wykorzystanym detektorem promieniowania gamma była komora jonizacyjna typu GW2 $[3,6]$. Jest to komora bezwodorowa $\mathrm{z}$ elektrodami wykonanymi $\mathrm{z}$ aluminium o grubości $1 \mathrm{~mm}$, wypełniona dwutlenkiem węgla o ciśnieniu 2,8 MPa i o czułości $256,67 \mathrm{pA} / \mathrm{mGy} \cdot \mathrm{h}^{-1}$. Pomiar odbywał się w trybie prądowym z wykorzystaniem elektrometru Keithley 6517B 
przy typowym napięciu pracy $\pm 30 \mathrm{~V}$, podczas którego zbierano kilkadziesiąt punktów pomiarowych w serii, a wynik przedstawiono jako średnią arytmetyczną z zebranych wartości wraz z odchyleniem standardowym wartości średniej. Stanowisko zbudowane zostało na bazie mobilnej konstrukcji warsztatowej o podwyższonej nośności z możliwością zmiany wysokości położenia półek. Badania wykonano w konfiguracji poglądowo przedstawionej na Rysunku 1. Seria pomiarowa rozpoczynała się od pomiaru prądu ciemnego, o którego wartość redukowano finalne wskazania podczas pomiarów dla płyt betonowych. Następnie na stanowisku wykonywano pomiar wartości prądu jonizacji płynącego przy ekspozycji samego źródła, bez próbek betonowych. Była to pierwsza wartość referencyjna. Po czym dokonywano pomiarów poprzez dokładanie, od strony źródła promieniowania, kolejnych próbek betonowych zwiększając w ten sposób grubość osłony.

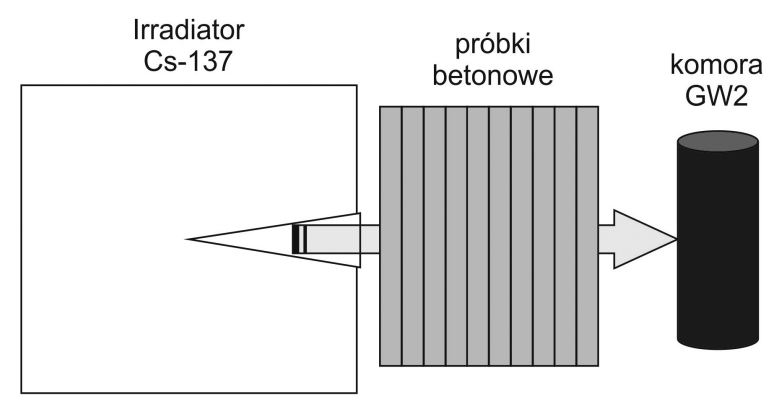

Rys. 1. Stanowisko badawcze do badania osłonności betonów przed promieniowaniem gamma

Fig. 1. Research stand for concrete shielding against gamma radiation

Płyty betonowe, przygotowane na potrzeby badania własności osłonowych, zostały wykonane $\mathrm{z}$ mieszanek sporządzonych według opracowanych receptur klasyfikujących je jako betony osłonowe, wykonane $\mathrm{z}$ betonu ciężkiego, o wymiarach 400 x 400 x $50 \mathrm{~mm}$, o gęstości objętościowej zależnej od rodzaju mieszanki, mieszczącej się w zakresie od 2192 do $3736 \mathrm{~kg} / \mathrm{m}^{3}$. Wykonanie próbek w takiej formie pozwoliło na badanie własności osłonnych w zależności od grubości badanej warstwy. Zapewnienie relatywnie dużej powierzchni badanego elementu w płaszczyźnie prostopadłej do wiązki wpływa korzystnie, ponieważ minimalizowany jest wpływ dodatkowych rozproszeń na krawędziach elementu jak również zapobiega się przedostaniu do przyrządu pomiarowego cząstek rozproszonych na innych elementach konstrukcji i pomieszczenia, w którym wykonywany jest eksperyment.

W przypadku pomiarów w źródle promieniowania gamma założono, że mierzony prąd jonizacji odpowiada intensywności wiązki promieniowania gamma, a zatem wyznaczenie parametrów TVL oraz HVL określono na podstawie standardowych definicji. Ze względu na wartości HVL, które na podstawie 
uzyskanych przebiegów wypadały poniżej grubości $50 \mathrm{~mm}$, zdecydowano się na metody interpolacji.

Wyznaczanie warstw połówkowych w polu promieniowania gamma przebiegło zgodnie $\mathrm{z}$ opracowanym postępowaniem:

a) odjęcie prądu ciemnego od i-tego wyniku pomiaru;

b) uśrednienie wartości otrzymanej dla napięcia dodatniego i ujemnego o tej samej wartości (30 V i -30 V);

c) normalizacja względem wartości maksymalnej (pomiar bez próbki) $\mathrm{I} / \mathrm{I}_{0}$;

d) zlogarytmowanie wartości względnej - otrzymanie równania liniowego;

e) wyznaczenie parametrów równania liniowego z sąsiedztwa sprawdzanego punktu (regresja liniowa);

f) wykorzystanie parametrów równania liniowego z punktu leżącego najbliżej wartości aktualnie obliczanej wartości połówkowej (np.: liczymy warstwę połówkową HVL1 - osłabienie 0,5: szukamy punktu dla zlogarytmowanej wartości względnej prądów zmierzonych, która ma wartość najbliżej sprawdzanego osłabienia i wykorzystujemy parametry równania liniowego do obliczenia ilości płyt potrzebnych do otrzymania takiej osłonności);

g) wyznaczamy grubości warstwy połówkowej;

h) kolejną warstwę połówkową (HVL2), czyli ponowne osłabienie poziomu promieniowania, obliczamy przez odjęcie zgodnie z puntami f) i g) oraz dodatkowo odejmujemy wartość warstwy połówkowej poprzedniej; w ten sposób zawsze wyznaczamy grubość osłony, która obniży pole promieniowania o połowę.

Znajomość kolejnych warstw półchłonnych pozwala określać współczynnik jednorodności promieniowania HF = HVL1/HVL2, którego znaczenie szerzej opisano w pracy [2].

\section{Wyniki i dyskusja}

Przebadano piętnaście rodzajów betonów różniących się m.in. zawartością kruszyw i gęstością objętościową. W Tabelach 2 i 3 zestawiono uproszczone składy przebadanych betonów.

Tabela 2. Uproszczone składy mieszanek betonowych I serii

Table 2. Simplified compositions of concrete mixtures in the first series

kruszywo magnetytowe

kruszywo barytowe

kruszywo serpentynitowe kruszywo amfibolitowe gęstość objętościowa $[\mathrm{kg} / \mathrm{m} 3]$

\begin{tabular}{|c|c|c|c|c|c|c} 
B1 & B4 & B5 & B6 & B8 & B9 & B10 \\
& & $\mathrm{X}$ & $\mathrm{X}$ & & $\mathrm{X}$ & $\mathrm{X}$ \\
$\mathrm{X}$ & & & & $\mathrm{X}$ & & $\mathrm{X}$ \\
2192 & $\mathrm{X}$ & & & & & \\
\end{tabular}


Tabela 3. Uproszczone składy mieszanek betonowych II serii

Table 3. Simplified compositions of concrete mixtures in the second series

kruszywo magnetytowe

kruszywo barytowe

kruszywo serpentynitowe

gęstość objętościowa $[\mathrm{kg} / \mathrm{m} 3]$

\begin{tabular}{|c|c|c|c|c|c|c|c} 
B11 & B12 & B13 & B14 & B15 & B16 & B17 & B18 \\
X & & X & X & & & & \\
& & & & $X$ & $X$ & $X$ & X \\
& $\mathrm{X}$ & $\mathrm{X}$ & $\mathrm{X}$ & & & $\mathrm{X}$ & $\mathrm{X}$ \\
3479 & 2289 & 3089 & 2708 & 3328 & 3168 & 2825 & 2606
\end{tabular}

$\mathrm{Na}$ podstawie przeprowadzonych pomiarów oraz przetwarzania danych pomiarowych otrzymano wartości grubości kolejnych warstw połówkowych i dziesięciochłonnych. Dane zestawiono w Tabelach 4 i 5.

Tabela 4. Zestawienie kolejnych wartości HVL oraz współczynnika jednorodności (HF) dla przebadanych betonów

Table 4. HVL values and homogeneity factor (HF) for tested concretes

\begin{tabular}{c|c|c|c|c|c|c|c|c|c|c|c|c|c|c|c} 
HVL1 & 4,0 & 3,8 & 2,7 & 2,8 & 3,9 & 2,8 & 2,9 & 2,7 & 4,3 & 3,2 & 3,7 & 2,8 & 2,9 & 3,3 & 3,6 \\
HVL2 & 4,1 & 3,9 & 2,7 & 2,8 & 4,0 & 3,0 & 3,1 & 2,7 & 4,2 & 3,0 & 3,6 & 2,7 & 2,8 & 3,2 & 3,6 \\
HF & 0,98 & 0,98 & 0,99 & 0,98 & 0,99 & 0,93 & 0,93 & 0,99 & 1,04 & 1,05 & 1,04 & 1,03 & 1,01 & 1,03 & 1,01
\end{tabular}

Tabela 5. Zestawienie kolejnych wartości TVL oraz współczynnika jednorodności (HF) dla przebadanych betonów

Table 5. TVL values and homogeneity factor (HF) for tested concretes

\begin{tabular}{c|c|c|c|c|c|c|c|c|c|c|c|c|c|c|c} 
& B1 & B4 & B5 & B6 & B8 & B9 & B10 & B11 & B12 & B13 & B14 & B15 & B16 & B17 & B18 \\
TVL1 & 13,8 & 13,0 & 9,0 & 9,3 & 13,5 & 9,7 & 10,5 & 9,0 & 13,8 & 10,0 & 11,8 & 9,0 & 9,5 & 10,5 & 11,9 \\
TVL2 & 15,1 & 13,9 & 9,2 & 9,7 & 14,3 & 10,3 & 11,2 & 9,0 & 13,7 & 9,8 & 11,6 & 8,9 & 9,5 & 10,5 & 11,8 \\
HF & 0,91 & 0,94 & 0,97 & 0,96 & 0,94 & 0,94 & 0,94 & 1,00 & 1,00 & 1,02 & 1,02 & 1,01 & 1,00 & 1,01 & 1,01
\end{tabular}

Z przeprowadzonych pomiarów wynika, iż najlepsze parametry osłonne w polu promieniowania gamma dla izotopu ${ }^{137} \mathrm{Cs}$ mają betony o oznaczeniach: B5, B11 i B15 (oznaczone w Tabelach 4 i 5 ciemnoszarym kolorem). W dwóch pierwszych (B5 oraz B11) zastosowano kruszywa magnetytowe, zaś w ostatnim wspomnianym - kruszywa barytowe. Wszystkie wyróżnione mieszanki betonowe charakteryzują się bardzo wysoką gęstością (powyżej $3300 \mathrm{~kg} / \mathrm{m}^{3}$ ). Z kolei najsłabiej wypadły mieszanki o oznaczeniach B1, B4, B8 oraz B12 (oznaczone w Tabelach 4 i 5 jasnoszarym kolorem). Są to mieszanki zawierające w składzie tylko kruszywa lekkie (serpentynit lub amfibolit) a ich gęstość nie przekracza $2450 \mathrm{~kg} / \mathrm{m}^{3}$. W celu zobrazowania danych wartości grubości HVL przedstawiono w postaci wykresu słupkowego na Rysunku 2. 


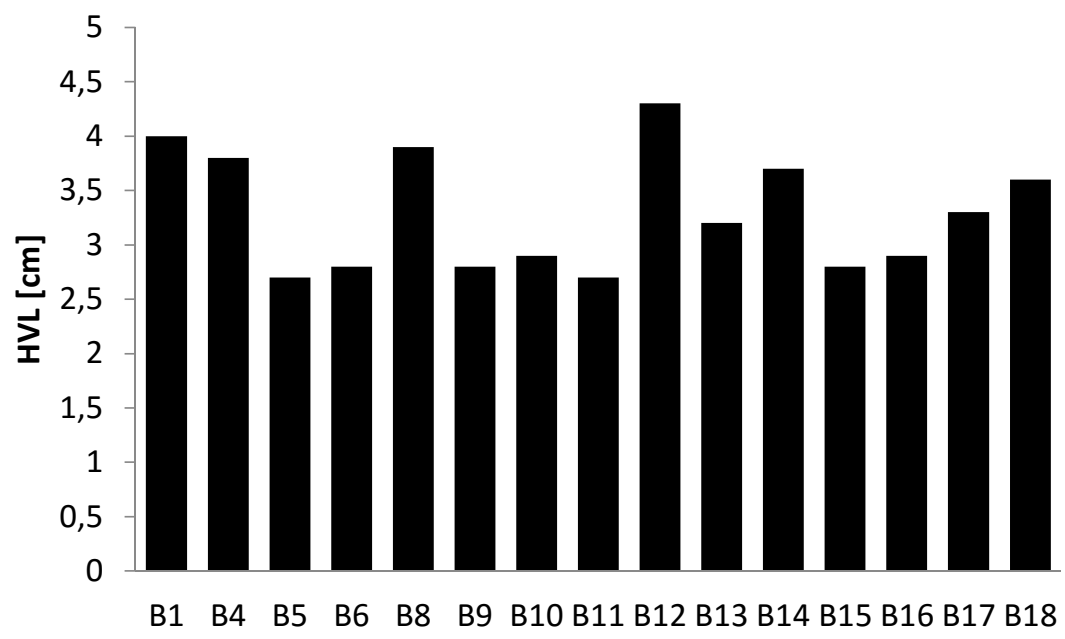

Rys. 2. Wartości HVL dla przebadanych rodzajów betonów

Fig. 2. HVL values for tested concrete mixtures

Dysponując wartościami gęstości poszczególnych betonów, które to bezpośrednio zależą od stosowanych kruszyw, wykreślono zależność grubości HVL od gęstości kolejnych betonów. Wartości te przedstawiono na Rysunku 3. Zgodnie $\mathrm{z}$ założeniami wraz ze wzrostem gęstości materiału osłonowego warstwa HVL (odpowiednio TVL) jest coraz cieńsza, co oznacza, że właściwości osłonowe materiału przed promieniowaniem gamma ulegają poprawie.

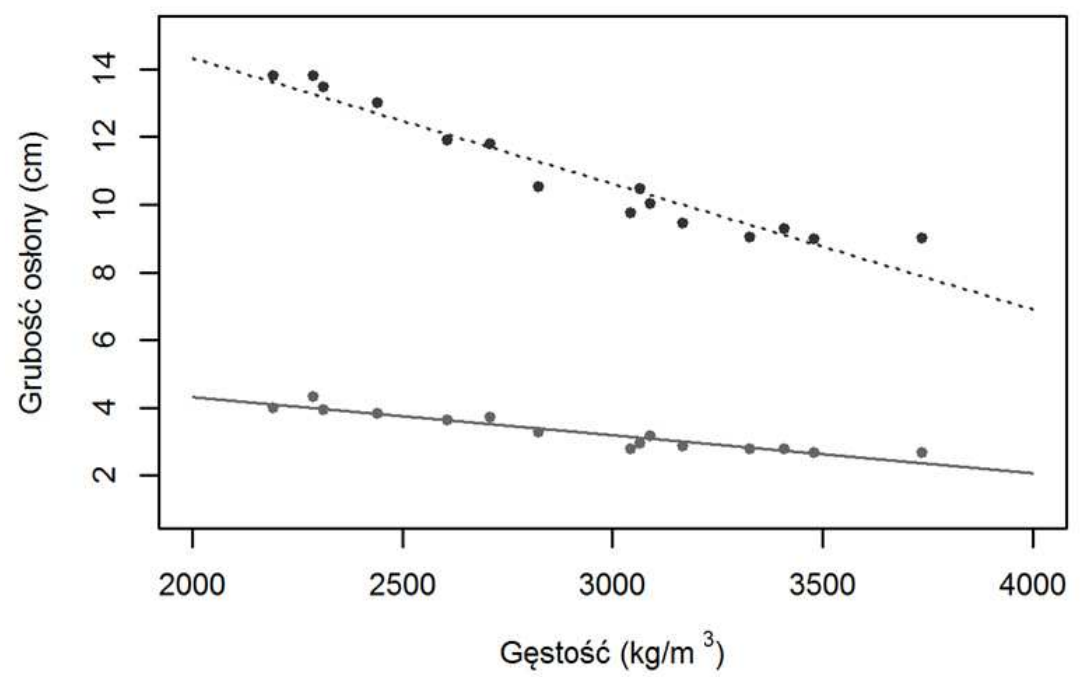

Rys. 3. Wartości HVL i TVL w funkcji gęstości objętościowej betonów

Fig. 3. HVL and TVL values presented as concrete density functions 
W praktyce ochrony radiologicznej na etapie obliczania osłon przed promieniowaniem gamma często używa się nomogramów przedstawiających krotności osłabienia osłony. Zebrane wyniki pozwoliły na wykreślenie krzywych tego typu. Jeden z otrzymanych nomogramów przedstawia Rysunek 4.

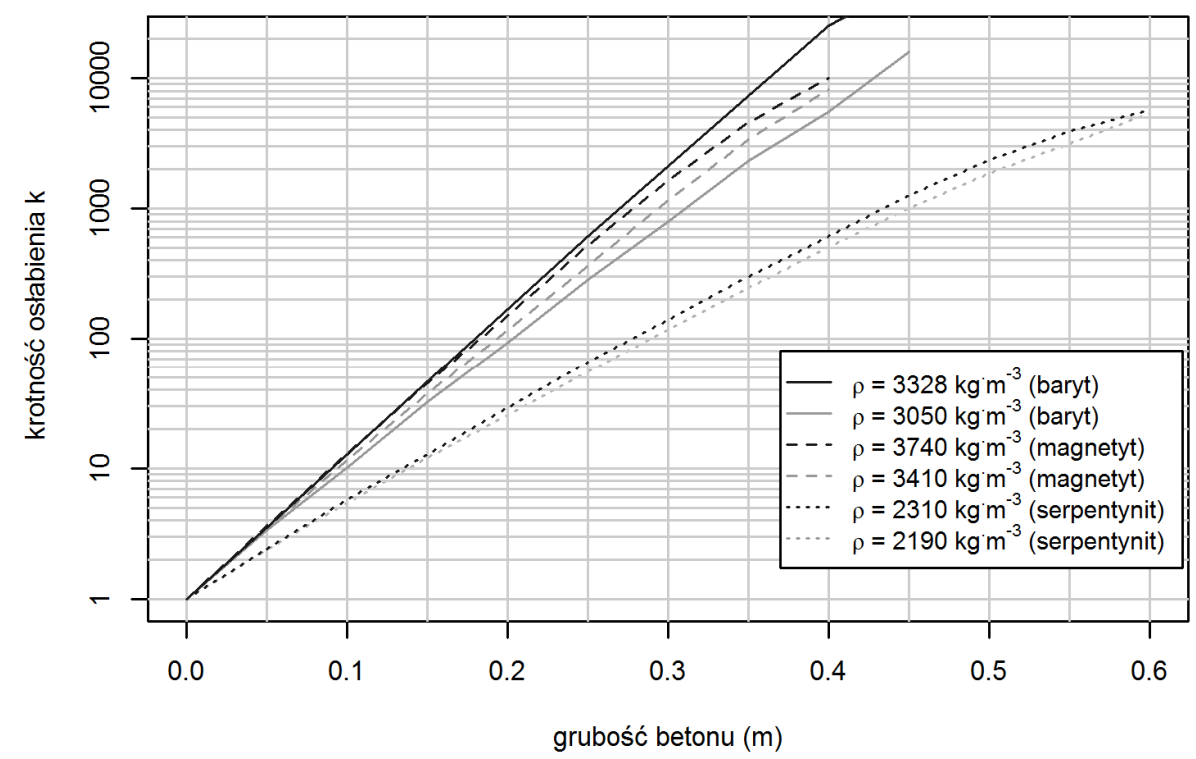

Rys. 4. Krotności osłabienia promieniowania gamma ${ }^{137} \mathrm{Cs}$ dla wybranych gęstości betonów osłonowych. W nawiasie podane jest kruszywo, na bazie którego beton został wykonany

Fig. 4. Attenuation factor for gamma radiation from ${ }^{137} \mathrm{Cs}$ for arbitrary selected concrete densities. In brackets are given aggregates used for particular concrete mix

Referat zostat przygotowany w ramach Projektu „Trwatość i skuteczność betonowych oston przed promieniowaniem jonizującym w obiektach energetyki jądrowej”, PBS II /A2/15/2014.

\section{Literatura}

[1] Brandt A. M.: Beton jako materiał osłon w budownictwie związanym z energetyką jądrową. Cement Wapno Beton, Polski Cement, 2, 115 - 132, 2013.

[2] Domański S., Gryziński M. A., Maciak M., Murawski Ł., Tulik P., Tymińska K.: Experimental investigation on radiation shielding of high performance concrete for nuclear and radiotherapy facilities, Pol. J. Med. Phys. Eng., Vol. 22, No2, 2016.

[3] Golnik N., Wysocka A., Zielczyński M.: Skuteczność zbierania jonów w komorze jonizacyjnej wypełnionej dwutlenkiem węgla pod ciśnieniem do miliona paskali, Raport INR 1925/XIX, Instytut Badań Jądrowych Świerk, 1982.

[4] Piasta J., Piasta W. G.: Rodzaje i znaczenie kruszywa w betonie, XVII Ogólnopolska Konferencja Warsztat Pracy Projektanta Konstrukcji. Ustroń 20-23 lutego 2002.

[5] Trout E.D., Kelly J.P., Lucas A.C.: Determination of Half-Value Layer, Am. J. Roentgenology, 85, p.933, 1960. 
[6] Zielczyński, M., Golnik, N., Gryziński, M. A., Tulik, P.: The use of recombination chambers at radiation therapy facilities, Radiation Measurements. 45, 1472-1475, 2010 .

\section{RADIATION SHIELDING EXAMINATION OF SPECIAL CONCRETES}

\section{S u m m a r y}

This paper focuses on the study of shielding properties of experimental concrete against gamma radiation, using a sealed radioactive ${ }^{137} \mathrm{Cs}$ source. For these analyzes a special measuring stand of specific geometry was prepared and described. The study used properly prepared heavy concrete samples of varying composition. Fifteen types of samples were tested with different concrete mixtures differing mainly in aggregates content and density. On the basis of the measurement data for different samples of concrete, the half-thickness layer (HVL) and tenth-thicknes layer (TVL) were obtained. Analyzes show that the best shielding parameters in the field of gamma radiation for the isotope ${ }^{137} \mathrm{Cs}$ are concrete types, where magnetite and barite aggregates were used. These mixtures have a very high density - more than $3300 \mathrm{~kg} / \mathrm{m}^{3}$. The mixtures containing only light aggregates (serpentine or amphibolite), with density below $2450 \mathrm{~kg} / \mathrm{m}^{3}$ were characterized by worse shielding parameters. The results obtained in accordance with prior assumptions, indicate that with the increase of the density of shielding material the HVL (or TVL respectively) thickness is reduced, which means that the shielding properties of the material against gamma radiation are improved.

Keywords: concrete, shielding, gamma radiation, experimental measurements

Przestano do redakcji: 07.06.2016 r.

Przyjęto do druku: $30.06 .2016 \mathrm{r}$.

DOI: $10.7862 / \mathrm{rb} .2016 .10$ 